\title{
Investigation of Temporal Apparent C4 Sugar Change in Manuka Honey
}

Anatoly Chernyshev*, Terry Braggins

Analytica Laboratories Ltd., Ruakura Research Centre, 10 Bisley Rd, Hamilton 3240, New Zealand

\section{Supplementary materials}

Table S1. The results of retesting a set of manuka honeys with Bruker Honey-Profiling ${ }^{\mathrm{TM}}$ NMR method (adopted from a conference presentation ${ }^{11}$ ).

\begin{tabular}{|c|c|c|c|c|c|c|c|c|}
\hline Sample \# & A & B & C & D & $\mathbf{E}$ & $\mathbf{F}$ & G & H \\
\hline$\delta^{13} C_{h}$ & -24.70 & -25.72 & -25.16 & -24.82 & -25.62 & -25.36 & -25.51 & -25.45 \\
\hline$\delta^{13} C_{p}$ & -27.06 & -27.61 & -26.91 & -26.18 & -26.61 & -26.03 & -27.24 & -26.10 \\
\hline Apparent C4 sugar \% & 13.6 & 10.6 & 10.2 & 8.3 & 5.9 & 4.1 & 9.9 & 4.0 \\
\hline DHA, mmol/kg & 4.9 & 4.2 & 5.7 & 20.0 & 23.1 & 30.1 & 5.0 & 28.0 \\
\hline MG, $\mathrm{mmol} / \mathrm{kg}$ & 8.5 & 10.6 & 13.0 & 5.5 & 5.0 & 6.1 & 11.8 & 6.2 \\
\hline HMF, mmol/kg & 0.9 & 0.6 & 0.7 & 0.1 & 0.1 & 0.1 & 0.7 & 0.1 \\
\hline \multicolumn{9}{|c|}{ Bruker Honey-Profiling ${ }^{\mathrm{TM}}$ NMR test results } \\
\hline Sugar syrups & No & No & Yes & No & No & No & No & No \\
\hline
\end{tabular}

01_NIUE_DHA

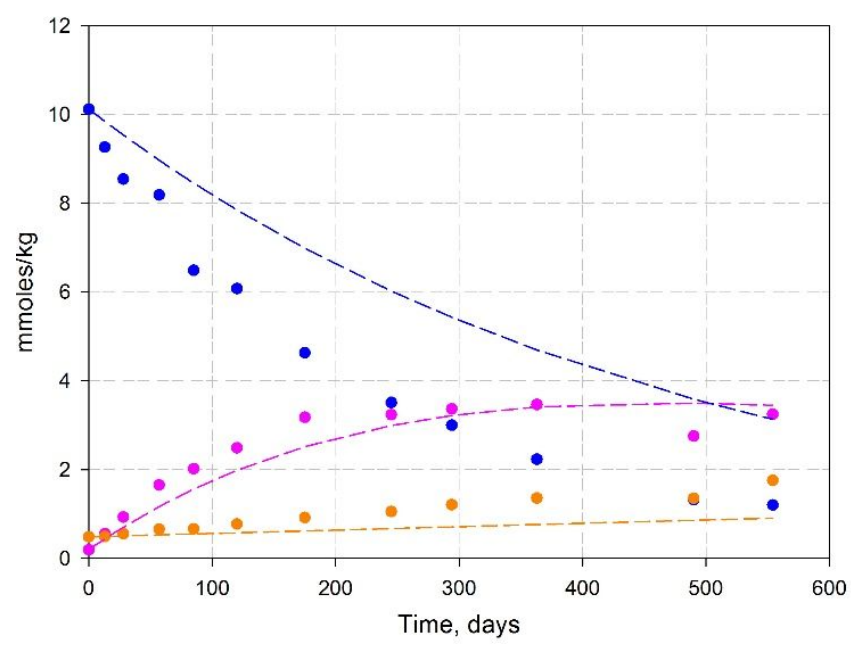

02_CLOVER_DHA

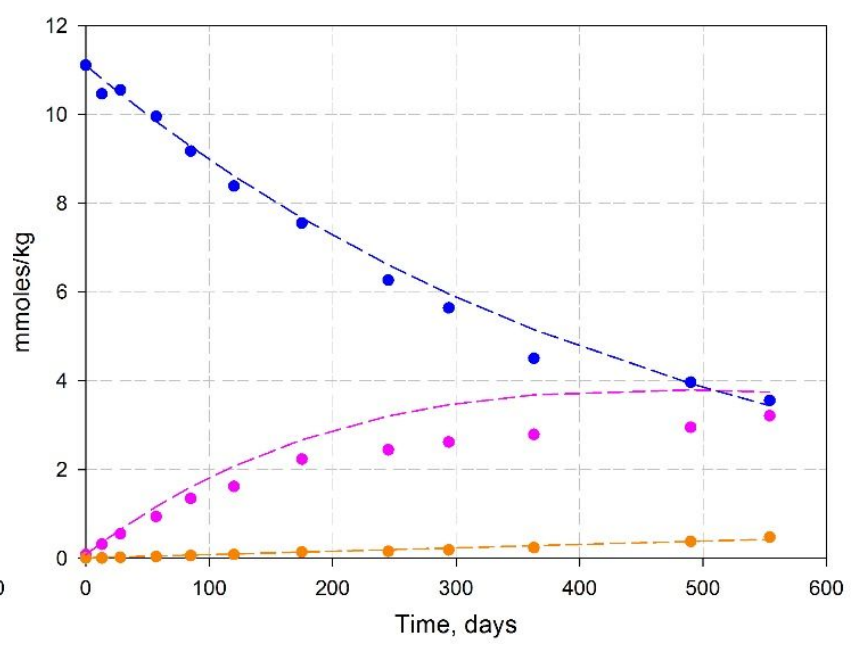




\section{4_MANUKA}

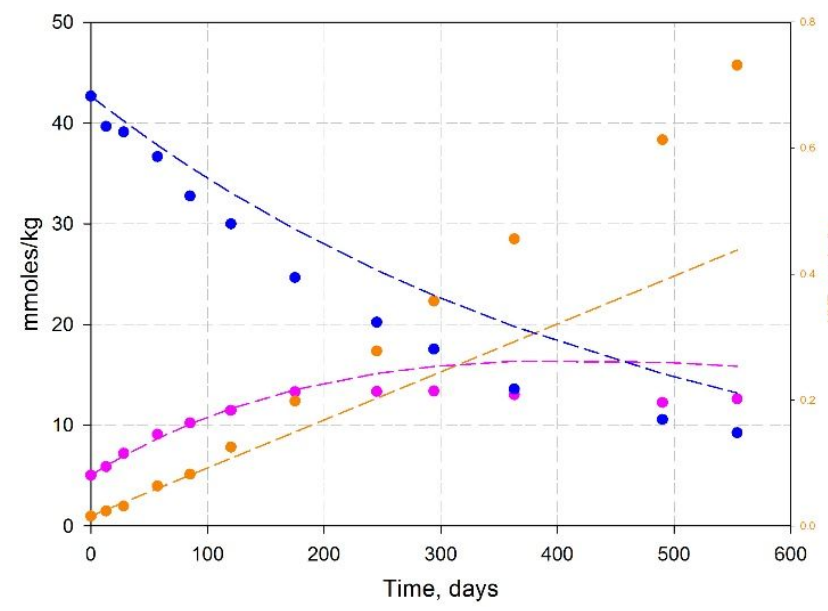

06_MANUKA

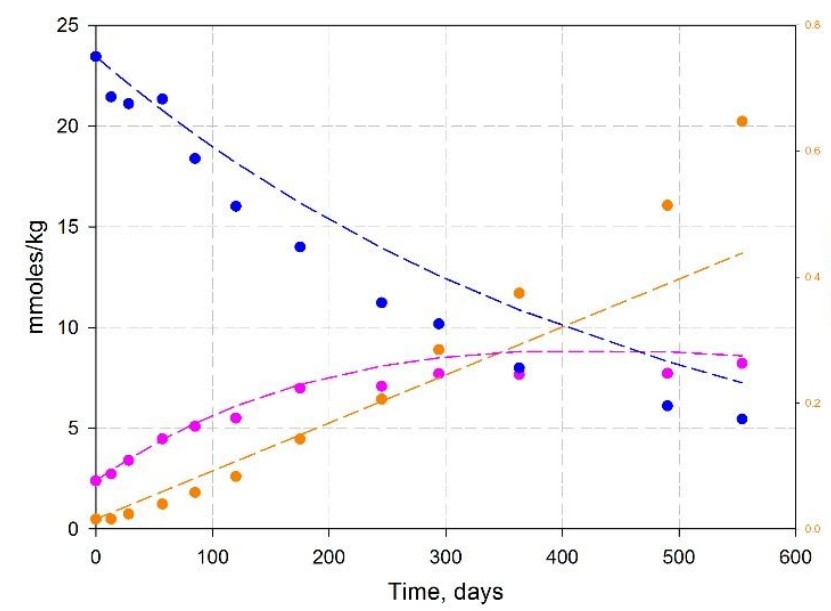

08_MANUKA_OLD

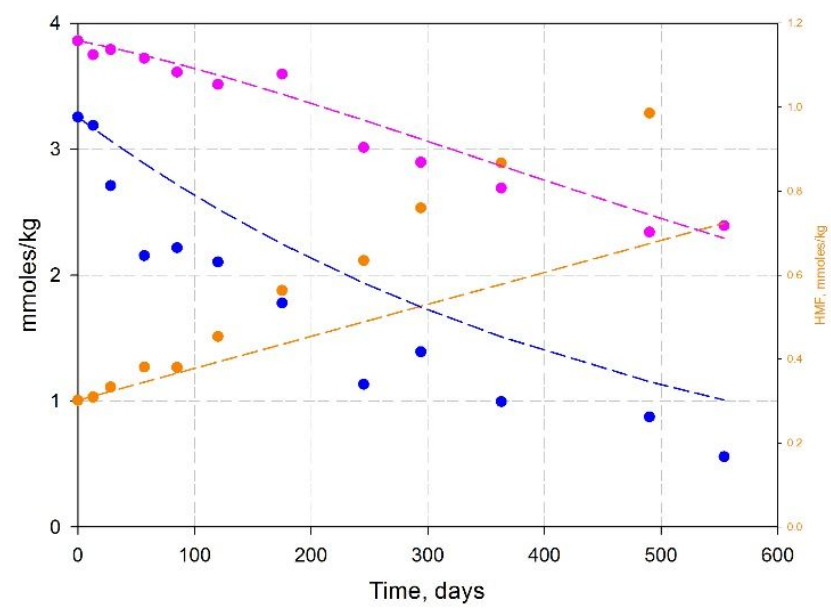

05_MANUKA

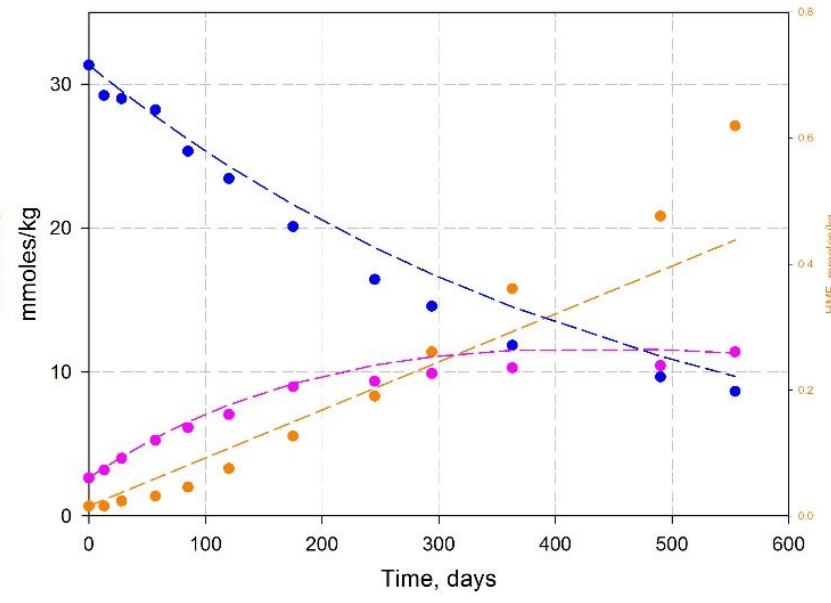

07_MANUKA

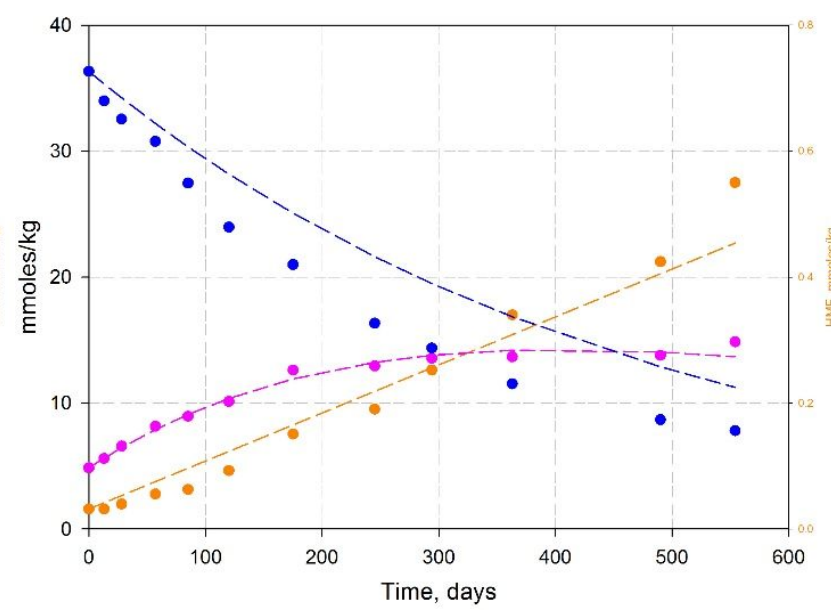

Figure S1. Change in concentrations of DHA (blue), MG (magenta), HMF (brown) over time in the studied honey samples. Dots - experimental values; dashed lines - forecast by Analytica's kinetic model. Sample \#3 (pure clover honey) is not shown. 


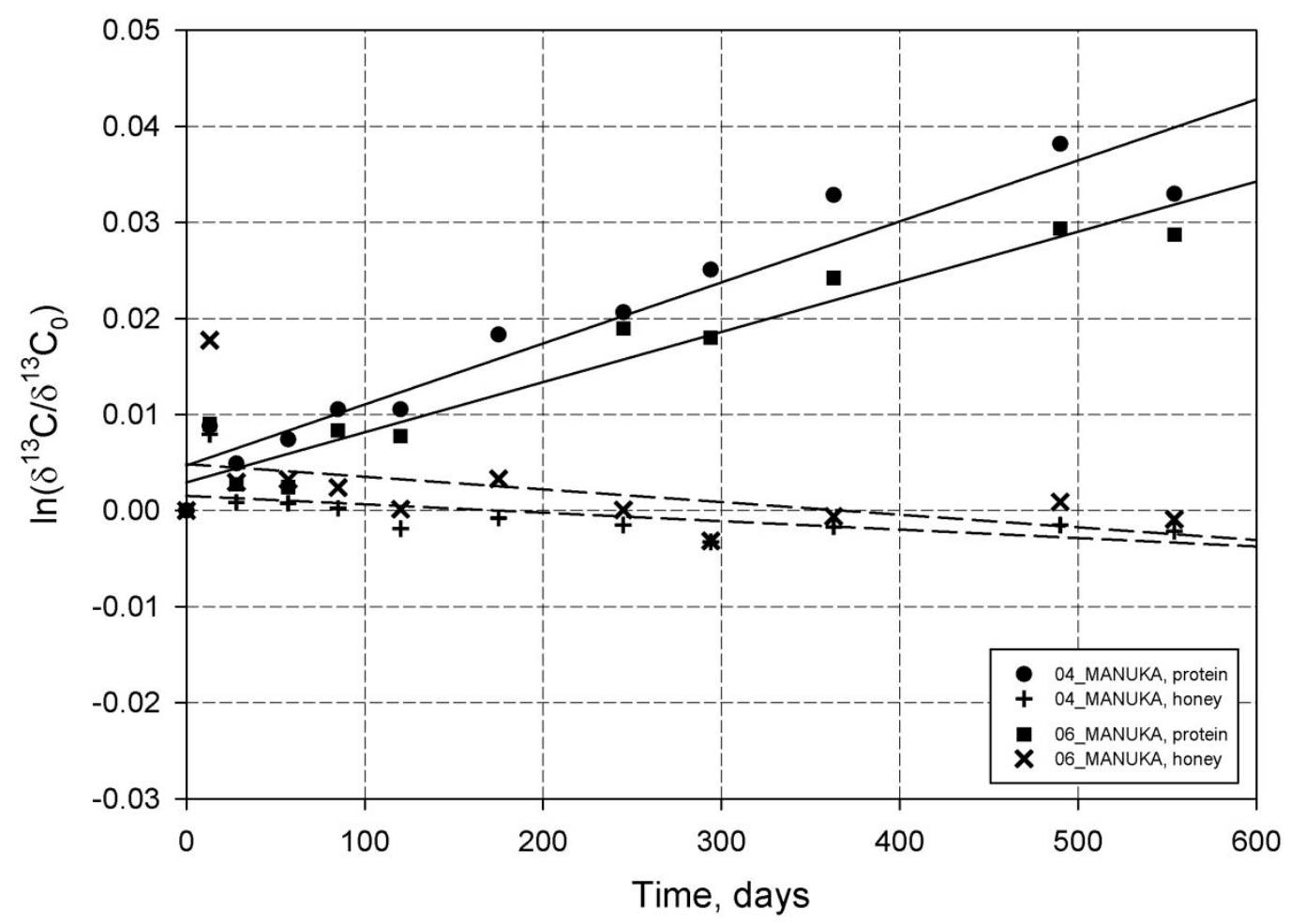

Figure S2. The plots of $\ln \left(\delta^{13} \mathrm{C} / \delta^{13} \mathrm{C}_{0}\right)$ vs. time for the other two high quality manuka honeys (group 3). The grey dashes are $95 \%$ confidence intervals.

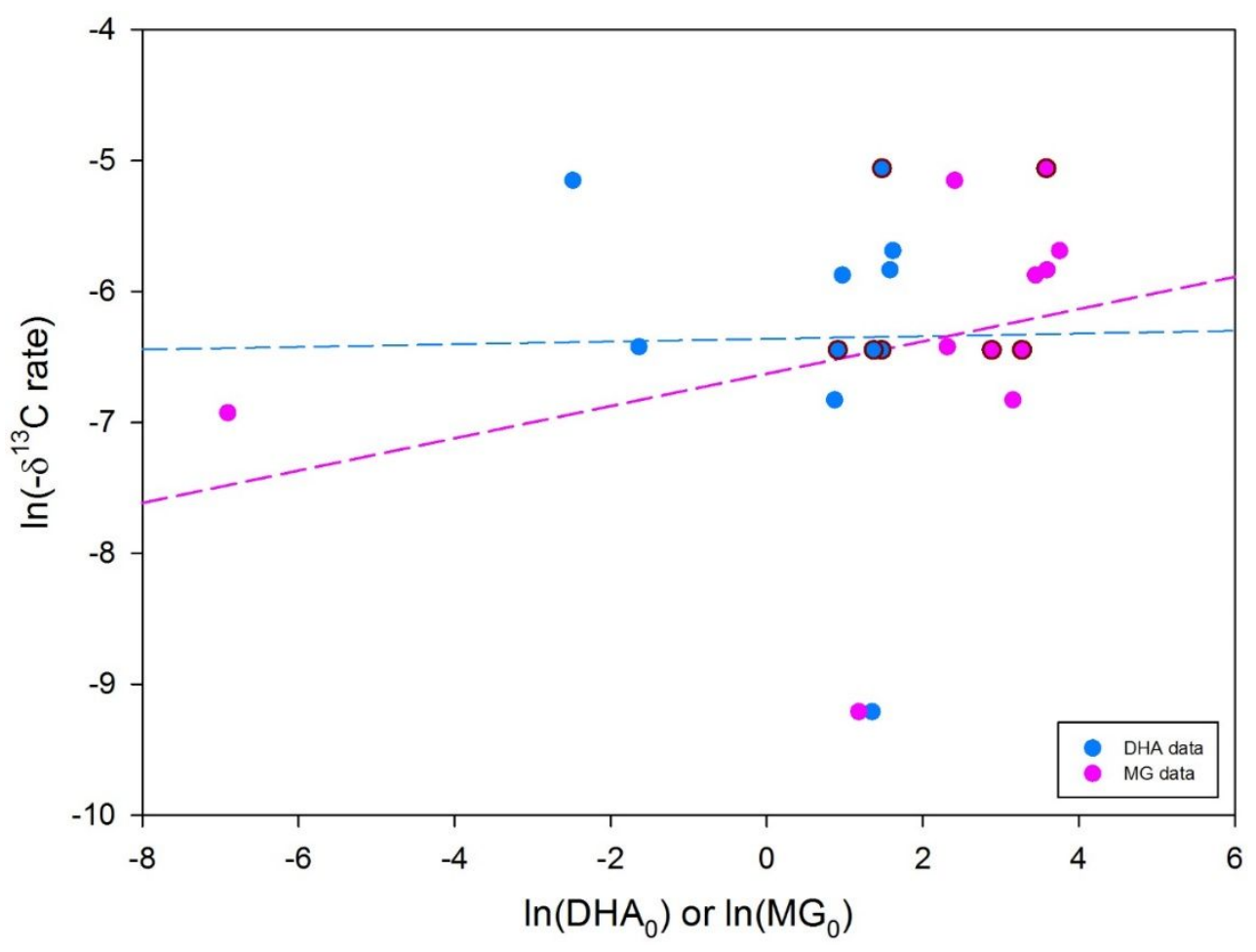

Figure S3. The plot of $\ln \left(-\mathrm{d} \delta^{13} \mathrm{Cp} / \mathrm{dt}\right)$ vs. $\ln \left(\mathrm{DHA}_{0}\right)$ and $\ln \left(\mathrm{MG}_{0}\right)$. The plot includes the data of Rogers ${ }^{1}$ (bordered circles). 
01_NIUE_DHA

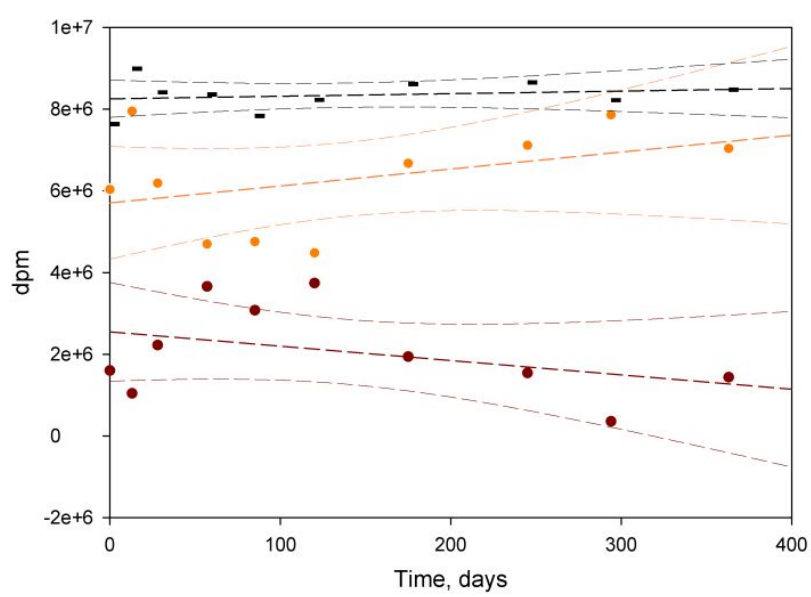

04_MANUKA

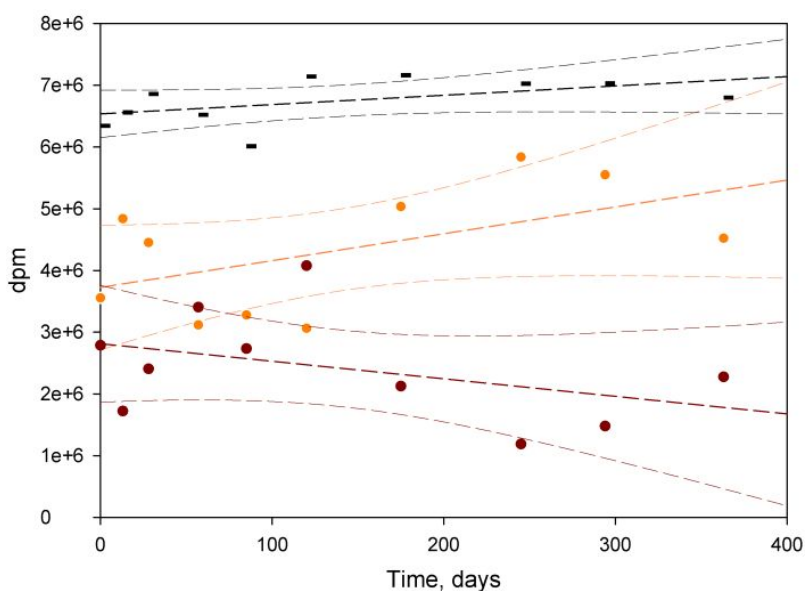

07_MANUKA

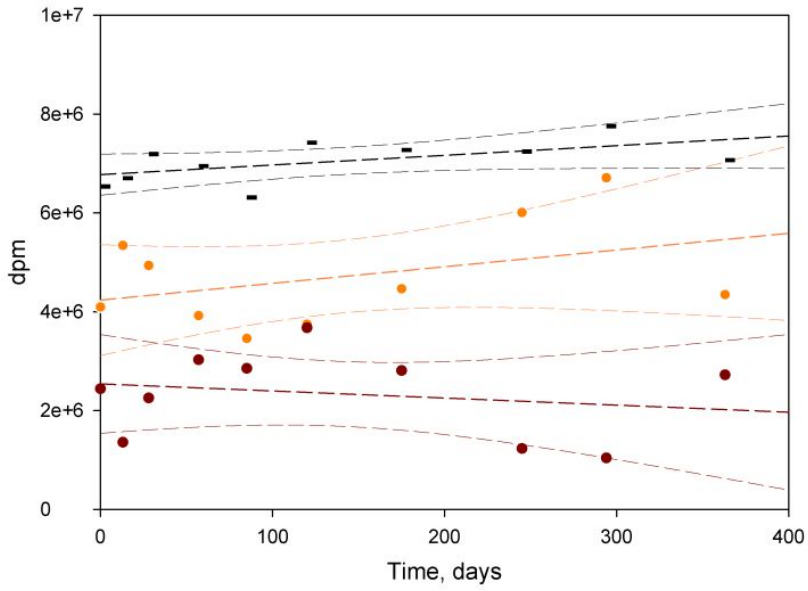

02_CLOVER_DHA

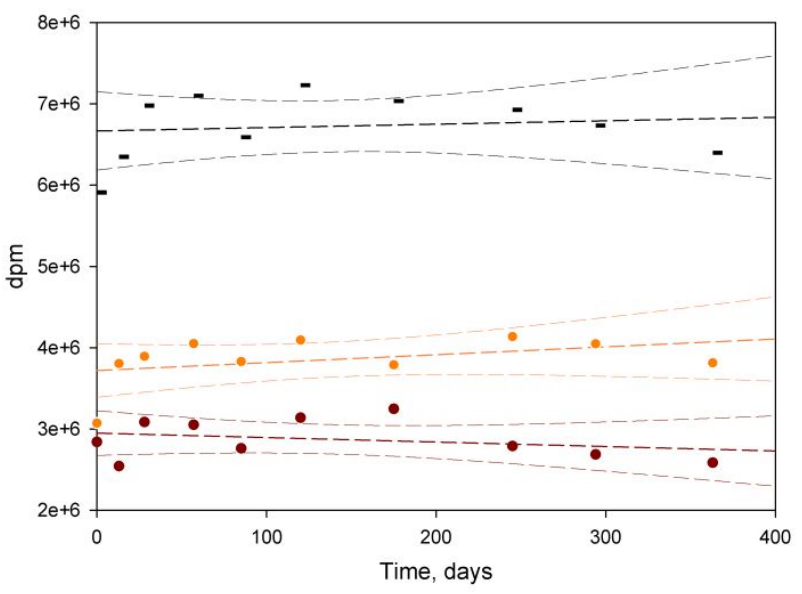

06_MANUKA

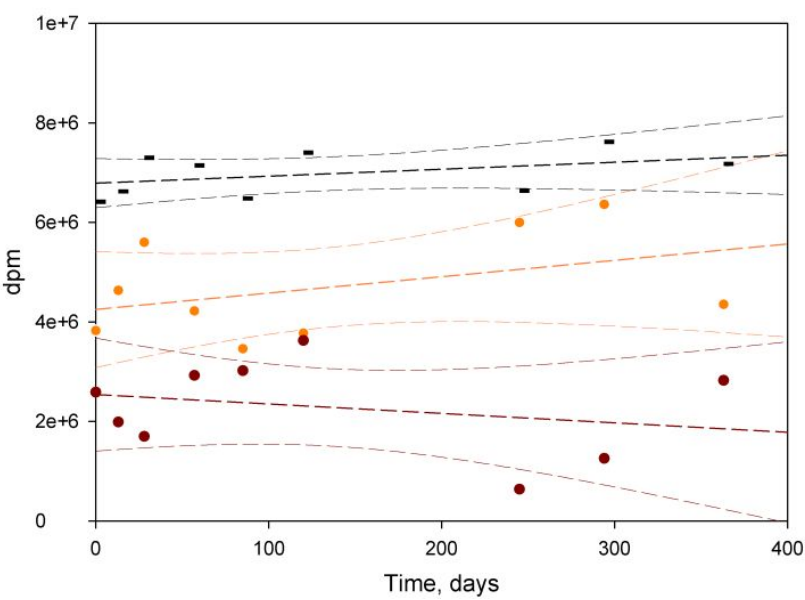

08_MANUKA_OLD

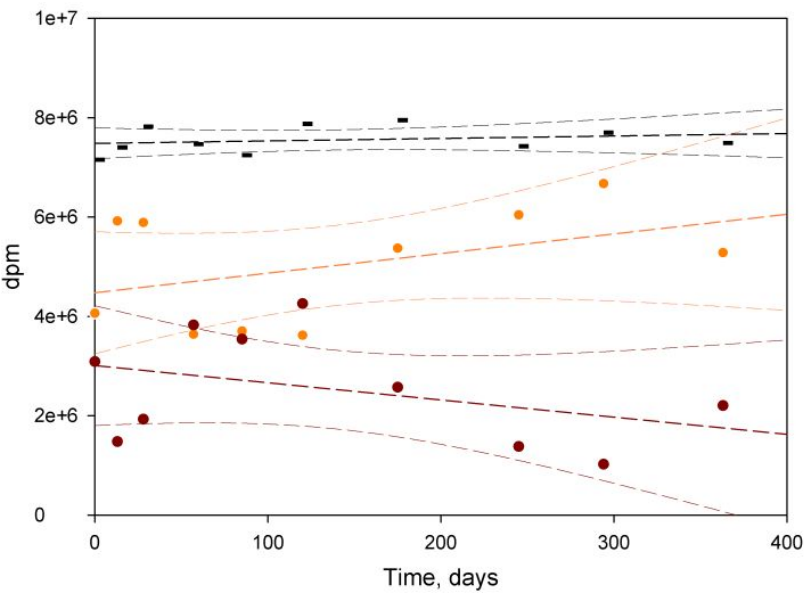

Figure S4. Change in scintillation counts, with 95\% confidence intervals, for honey (light brown), protein (dark brown), and total (black) over time in the studied honey samples. The black dashes show the total amount of ${ }^{14} \mathrm{C}$ label in the sample, and serve as a control to check in there was any loss of the labelled material during the protein precipitation. 
Table S2. The results of isotopic headspace analysis of the honey samples.

\begin{tabular}{|l|c|c|c|}
\hline \multicolumn{1}{|c|}{ Sample ID } & $\mathbf{O}_{\mathbf{2}}, \boldsymbol{\%}$ & $\mathbf{C O}_{\mathbf{2}}, \mathbf{p p m}$ & $\boldsymbol{\delta}^{\mathbf{1 3}} \mathbf{C}$ \\
\hline Laboratory air & 20.5 & 770 & -23.4 \\
\hline 01_NIUE_DHA & 20.3 & 1260 & -27.6 \\
\hline 02_CLOVER_DHA & 19.2 & 1500 & -29.8 \\
\hline 03_CLOVER & 19.3 & 6530 & -26.4 \\
\hline 04_MANUKA & 18.8 & 12110 & -35.2 \\
\hline 05_MANUKA & 18.4 & 4840 & -35.0 \\
\hline 06_MANUKA & 18.0 & 12300 & -37.8 \\
\hline 07_MANUKA & 19.3 & 1200 & -25.7 \\
\hline 08_MANUKA_OLD & 19.2 & 6240 & -34.9 \\
\hline $\begin{array}{l}\text { Fresh, non-incubated } \\
\text { manuka honey* }\end{array}$ & 20.3 & 1540 & -27.1 \\
\hline
\end{tabular}

Table S3. The results of $\delta^{13} \mathrm{C}$ measurements in artificial honey. Highlighted bold is the component changing its isotopic composition.

\begin{tabular}{|c|c|c|c|}
\hline Time & Sample & $\delta^{13} \mathrm{C}$ & $\sigma\left(\delta^{13} \mathrm{C}\right)$ \\
\hline Day 0 & Artificial Honey + DHA & -12.28 & 0.02 \\
& Artificial Protein + DHA & -10.00 & 0.02 \\
& Artificial Honey - DHA & -12.17 & 0.07 \\
& Artificial Protein - DHA & -9.99 & 0.03 \\
& & & 0.04 \\
\hline \multirow{2}{*}{ Day 7 } & Artificial Honey + DHA & -12.32 & 0.02 \\
& Artificial Protein + DHA & -10.71 & 0.05 \\
& Artificial Honey - DHA & -12.28 & 0.08 \\
\hline
\end{tabular}

